\title{
Mitotic Figure Assessment
}

National Cancer Institute

\section{Source}

National Cancer Institute. Mitotic Figure Assessment. NCI Thesaurus. Code C135470.

An evaluation of the presence or degree of mitotic figures present in a sample. 